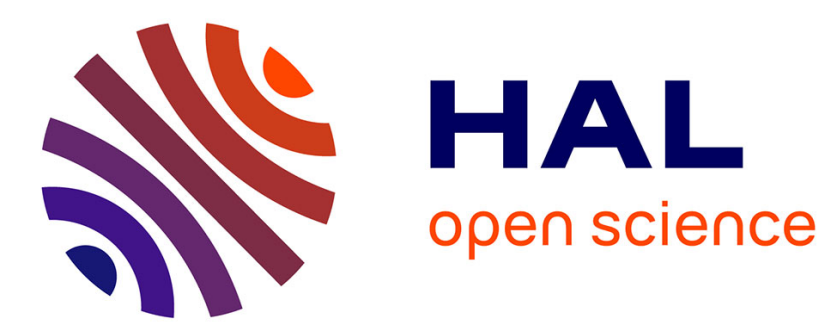

\title{
Effect of thermal treatments on the low temperature specific heat of $\mathrm{B} 2 \mathrm{O} 3$ and $\mathrm{SiO} 2$ glasses
}

J.C. Lasjaunias, G. Penn, A. Ravex, M. Vandorpe

\section{To cite this version:}

J.C. Lasjaunias, G. Penn, A. Ravex, M. Vandorpe. Effect of thermal treatments on the low temperature specific heat of $\mathrm{B} 2 \mathrm{O} 3$ and $\mathrm{SiO} 2$ glasses. Journal de Physique Lettres, 1980, 41 (6), pp.131-133. 10.1051/jphyslet:01980004106013100 . jpa-00231740

\section{HAL Id: jpa-00231740 https://hal.science/jpa-00231740}

Submitted on 1 Jan 1980

HAL is a multi-disciplinary open access archive for the deposit and dissemination of scientific research documents, whether they are published or not. The documents may come from teaching and research institutions in France or abroad, or from public or private research centers.
L'archive ouverte pluridisciplinaire HAL, est destinée au dépôt et à la diffusion de documents scientifiques de niveau recherche, publiés ou non, émanant des établissements d'enseignement et de recherche français ou étrangers, des laboratoires publics ou privés. 


\title{
LE JOURNAL DE PHYSIQUE-LETTRES
}

\section{Effect of thermal treatments on the low temperature specific heat of $\mathrm{B}_{2} \mathrm{O}_{3}$ and $\mathrm{SiO}_{2}$ glasses}

\author{
J. C. Lasjaunias, G. Penn, A. Ravex and M. Vandorpe \\ Centre de Recherches sur les Très Basses Températures, C.N.R.S., BP 166X, 38042 Grenoble Cedex, France
}

(Reçu le 20 décembre 1979, accepté le 25 janvier 1980)

\begin{abstract}
Résumé. - On a mesuré la chaleur spécifique entre 0,1 et 1 ou $2 \mathrm{~K}$ des verres $\mathrm{B}_{2} \mathrm{O}_{3}$ et $\mathrm{SiO}_{2}$ soumis à des traitements thermiques de stabilisation au voisinage de $T g$. Bien que des variations permanentes de densité jusqu'à $2 \%$ aient été obtenues dans le cas de $\mathrm{B}_{2} \mathrm{O}_{3}$, cela ne produit que de faibles modifications de la chaleur spécifique liée aux systèmes à deux niveaux.

Abstract. - Specific heat measurements have been performed between 0.1 and 1 or $2 \mathrm{~K}$ on $\mathrm{B}_{2} \mathrm{O}_{3}$ and $\mathrm{SiO}_{2}$ glasses, which were stabilized near $T g$ by thermal treatments. Although permanent variations of the density up to two per-cent were obtained for $\mathrm{B}_{2} \mathrm{O}_{3}$, this induced only a slight modification of the specific heat related to the twolevel systems.
\end{abstract}

1. Introduction. - In this paper we report a series of experiments to test the effect of thermal treatments on the low temperature specific heat of two oxide glasses of very different structure : $\mathrm{B}_{2} \mathrm{O}_{3}$ and $\mathrm{SiO}_{2}$. The specific heat below $1 \mathrm{~K}$ gives direct information on the density of states of the low-energy excitations characteristic of the vitreous state [1], and so these experiments should demonstrate the sensitivity of the density of states to special physical treatments. In particular we have studied the effect of thermal treatments near the glass transition temperature which involve modifications of the metastable state of the glass, in the hope that this will throw some light on the structural nature of the excitations.

2. Thermal treatments. - The general procedure is the following : we have subjected to successive treatments a sample previously measured in an initial state ; we used the same sample in order to eliminate variations of the properties which can occur with different samples, even of the same material. Each treatment consists in stabilization at a given temperature for a sufficiently long time to establish structural equilibrium, followed by quenching; so each treatment is characterized by a fictive temperature $T_{\mathrm{f}}$. The density is measured after each treatment.

$\mathrm{B}_{2} \mathrm{O}_{3}$ : the initial sample is that specified as $n^{0} 1$ in reference [2] where the method of preparation and the specific heat results are reported. This sample, in the form of a rod $2 \mathrm{~cm}$ in diameter, $\sim 8 \mathrm{~cm}$ long, had been annealed for $10-15 \mathrm{~h}$ at $250^{\circ} \mathrm{C}$ and cooled slowly to room temperature [2].

Two successive stabilizations were carried out the first at $250^{\circ} \ddot{\mathrm{C}}$ for $150 \mathrm{~h}$, the second at $310^{\circ} \mathrm{C}$ for $14 \mathrm{~h}$, both in high vacuum; these times were determined from relaxation measurements of optical properties [3]. Both stabilizations were followed by quenching in oil (butylphtalate). Cracks due to internal strains appeared in the bulk during the first quench and further developed during the second.

$\mathrm{SiO}_{2}$ : the initial sample was the Suprasil W $(\mathrm{OH}$ content $\lesssim 1.5 \mathrm{ppm}$ ) specified as $\mathrm{n}^{\circ} 1$ in reference [4]. Thermal treatments have been carried out at the two temperatures of 1100 and $1300{ }^{\circ} \mathrm{C}$ on several samples cut from the initial one, either in the form of bulk rods or in slices. We report here preliminary results obtained with slices treated ${ }^{\prime}$ at $1300^{\circ} \mathrm{C}$. The procedure was the following : a part of the initial sample in the form of a rod of $2 \mathrm{~cm}$ diameter, $5 \mathrm{~cm}$ long, was stabilized at $1300^{\circ} \mathrm{C}$ for $6 \mathrm{~h}$ in high vacuum, and then quenched in water. Then slices of about $1 \mathrm{~mm}$ thick were cut from this rod and subjected for additional time $(24 \mathrm{~h})$ for a stabilization at $1300{ }^{\circ} \mathrm{C}$ in the same conditions. Traces of surface crystallinity of the cristobalite phase were removed by HF acid or scraped off mechanically and each slice tested by X-rays before the measurements. 
3. Density variations. - The dependence of the density of the quenched material with the fictive temperature $\rho\left(T_{\mathrm{f}}\right)$ depends on the structure of the super-cooled liquid at the corresponding stabilization temperature. For vitreous silica the variation is positive, corresponding to a negative thermal expansion : this behaviour is anomalous in comparison to common silicate glasses and different interpretations have been suggested $[5,6]$. For $\mathrm{B}_{2} \mathrm{O}_{3}$ this variation is negative but the amplitude of variation is very large compared to sodium or potassium silicate glasses, in a ratio of 100 larger than for $\mathrm{SiO}_{2}[7,8]$.

After each thermal treatment, the room temperature density $\left(d_{4}^{20}\right)$ was measured by the flotation method using water for silica and trichloroethylene for $\mathrm{B}_{2} \mathrm{O}_{3}$. The density of the initial sample of $\mathrm{B}_{2} \mathrm{O}_{3}$ was $1.8285 \pm 0.0005 \mathrm{~g} / \mathrm{cm}^{3}$. The first stabilization at $250{ }^{\circ} \mathrm{C}$ for $150 \mathrm{~h}$ did not induce detectable variation, but after the stabilization at $310^{\circ} \mathrm{C}$ the density is lowered to $1.7900 \pm 0.0005$, a reduction of about $2 \%$. These values are in fair agreement with those of Eversteijn et al. [7] who also measured the room temperature density of the quenched glass. The density of the initial sample of silica was

$$
2.2028 \pm 0.0002 \mathrm{~g} / \mathrm{cm}^{3},
$$

and that of the slices stabilized at $1300{ }^{\circ} \mathrm{C}$ :

$$
2.2075 \pm 0.0005 \mathrm{~g} / \mathrm{cm}^{3} \text {, }
$$

an increase of about $0.2 \%$.

4. Specific heat results and discussion. - The general technique of the specific heat measurements has been described elsewhere $[2,9]$. For the $\mathrm{B}_{2} \mathrm{O}_{3}$ sample, we did not use a permanent heat link but a superconducting thermal switch, which limits the lowest temperature measurements to $0.1 \mathrm{~K}$. For the silica slices, the total amount of material being only $8 \mathrm{~g}$, we used a different sample arrangement where the slices are pressed between two slabs of silicon on which are fixed the different addenda : thermal link, heater and thermometer, here a piece of doped silicon. The uncertainty in the value of the addenda, in comparison to that of the sample, limits at present the available data to the lowest temperature of $80 \mathrm{mK}$.

\section{a) $\mathrm{B}_{2} \mathrm{O}_{3}$ :}

The specific heat results for the initial sample are reported in figure 1 together with those obtained after the two successive thermal treatments. A very slight variation is observed, a maximum increase of $10 \%$ in $C_{p}$ after the second stabilization at $310^{\circ} \mathrm{C}$. In this temperature range, principally below $0.5 \mathrm{~K}$ for $\mathrm{B}_{2} \mathrm{O}_{3}$, the main contribution to the specific heat is that of the excitations characteristic of the vitreous state, generally assigned to two-level systems (TLS) $[11,12]$. We verify that their density of states down to an energy $E / k_{\mathrm{B}} \sim 0.25 \mathrm{~K}$, corresponding to the

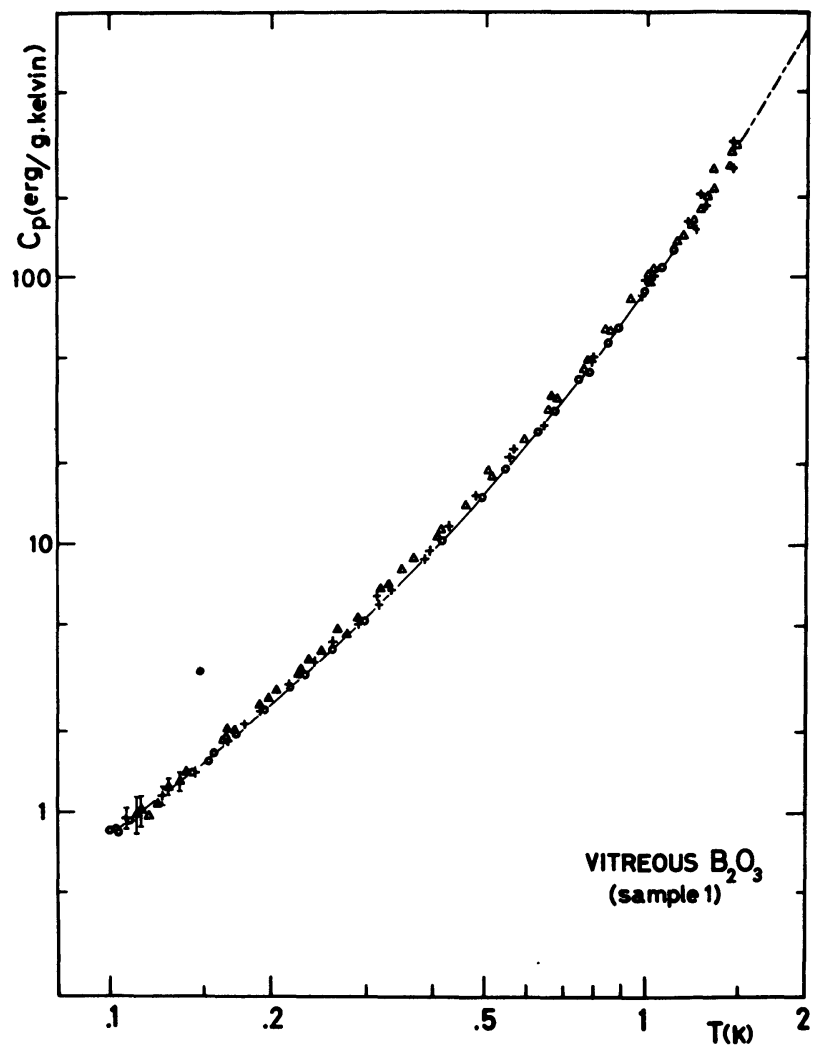

Fig. 1. - Specific heat of $\mathrm{B}_{2} \mathrm{O}_{3}$ in the initial state (sample 1 in reference [2]) represented by the symbol $O$ and the solid line, and after the two successive stabilizations at $250^{\circ} \mathrm{C}(+)$ and $310^{\circ} \mathrm{C}$ $(\triangle)$. The dashed line above $1.5 \mathrm{~K}$ represents the results of A. P. Jeapes $[10]$.

lowest temperature $\sim 0.1 \mathrm{~K}$, is relatively insensitive to large variations of the macroscopic density or to the presence of strains.

From the variations of the density and specific heat we can obtain an upper-estimate of the Grüneisen parameter associated with these excitations, using in this low temperature range the general formula :

$$
\frac{\partial \ln C_{i}}{\partial \ln \rho}=-\gamma_{i} \frac{\partial \ln C_{i}}{\partial \ln T}
$$

where the index $i$ referes to the contribution $i$ in the specific heat. For the two-level systems, $C_{i} \simeq a T^{1.5}$ in the case of $\mathrm{B}_{2} \mathrm{O}_{3}$ [2]. A maximum increase of $10 \%$ of $C$ related to a decrease of $2 \%$ for $\rho$ leads to a positive value of $\gamma$ with a maximum value of 3 . This is in disagreement with a recent hypothesis of Lyon et al. [13] who suggest that a large negative value of about - 16, corresponding to thermal expansivities measurements below $4 \mathrm{~K}$ in vitreous silica and PMMA, should be a general feature for the amorphous materials.

\section{b) $\mathrm{SiO}_{2}$ :}

A more complete discussion taking into account the results on the bulk rods stabilized at 1100 and 
$1300{ }^{\circ} \mathrm{C}$ and the slices at $1100{ }^{\circ} \mathrm{C}$ will be presented in a next paper. However the partial data reported here in figure 2 for the slices treated at $1300^{\circ} \mathrm{C}$, for which the maximum variation of density in comparison to the initial sample was observed, enable us to draw certain conclusions. We distinguish two temperature ranges where the effects are highly different :

1) Below 0.5-0.6 K and down to $0.1 \mathrm{~K}$, the thermal treatment induces a small increase of $C_{p}$, of at most $10 \%$ near $0.2 \mathrm{~K}$, a little above the uncertainty of the experiment which we estimate of about $5 \%$ in this case. In this temperature range the main contribution to $C_{p}$ is that of the TSL excitations and their density of states in the corresponding energy range appears to be slightly dependent of this thermal treatment, in agreement with the results in boron oxide.

We can estimate the effect of densification alone on the specific heat from the Grüneisen parameter in formula (1). For vitreous silica recent precise measurements give for the $\gamma_{i}$ related to the TLS excitations a value of -16 [13]; for a densification of $0.2 \%$, assuming in a first approximation a linear variation $C_{i}(T)$, the effect would result in an increase of $3 \%$ of $C_{i}$ which cannot be detected from the uncertainty of the measurements.

2) Between 0.5 and $2 \mathrm{~K}$ a strong decrease appears. Apparently this effect is not correlated with the TLS : for Suprasil W a bump in $C_{p}$ exists in this temperature range in contrast to all other types of vitreous silica (including Suprasil with hydroxyl content [4]). Its physical origin is not still clear, but we establish that the present thermal treatment is sufficient to totally remove this excess, as the actual values are now in good agreement with the other types of silica : Suprasil II [4], Spectrosil B [14], and IR Vitreosil - $1000^{\circ} \mathrm{C}$ [15] above $1.5 \mathrm{~K}$. A more complete analysis of this effect will be reported in the next paper.

In conclusion, we have observed in these two different species of glass a slight effect of thermal treatment on the specific heat between 0.1 and $0.5 \mathrm{~K}$ in the case of $\mathrm{SiO}_{2}$, or $1 \mathrm{~K}$ in the case of $\mathrm{B}_{2} \mathrm{O}_{3}$. The treatment resulted in variations of the density of opposite sign and of strongly different magnitude for

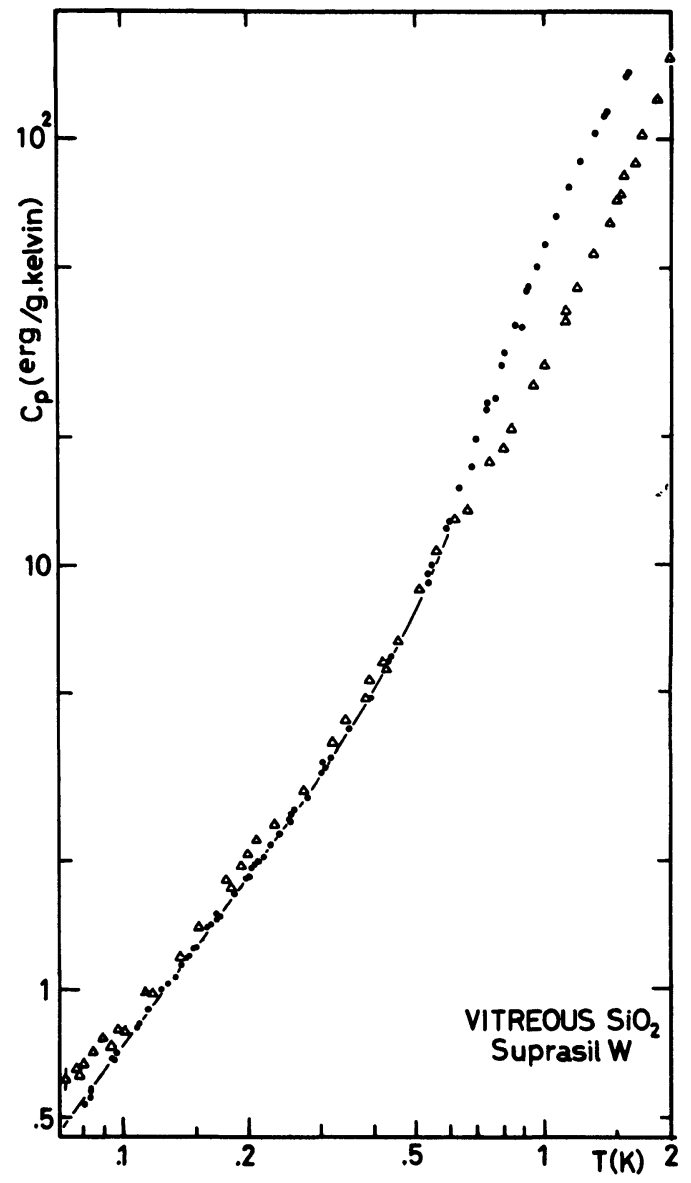

Fig. 2. - Specific heat of $\mathrm{SiO}_{2}$, Suprasil-W type, in the initial state from reference [4] (symbol $\bullet$ and solid line below $0.5 \mathrm{~K}$ ) and after stabilization at $1300^{\circ} \mathrm{C}$ for the sample in the form of slices $(\triangle)$.

the two glasses, and also in the appearance of strains (mainly for $\mathrm{B}_{2} \mathrm{O}_{3}$ ). In both cases the density of states of the low energy excitations appears to be relatively insensitive in the corresponding range of energy to such physical modifications : that is rather surprising in the framework of the double-well tunneling model for which one could expect a dependence of these configurational excitations upon parameters such as the density.

\section{References}

[1] For a recent review see, for example, Phillips, W. A., J. Non-Cryst. Solids 31 (1978) 267.

[2] Lasjaunias, J. C., Thoulouze, D. and Pernot, F., Solid State Commun. 14 (1974) 957.

[3] Boesch, L., Napoltano, A. and Macedo, P. B., J. Am. Ceram. Soc. 53 (1970) 148.

[4] Lasjaunias, J. C., RaveX, A., Vandorpe, M. and HunklinGER, S., Solid State Commun. 17 (1975) 1045.

[5] Douglas, R. W. and Isard, J. O., J. Soc. Glass Technol. 35 (1951) 206T.

[6] BRÜCKNeR, R., J. Non-Cryst. Solids 5 (1970) 123.

[7] Eversteijn, F. C., Stevels, J. M. and Waterman, H. I., Phys. Chem. Glasses 1 (1960) 123.
[8] Krogh-Moe, J., J. Non-Cryst. Solids 1 (1969) 269.

[9] Lasjaunias, J. C., Picot, B., Ravex, A., Thoulouze, D. and VANDORPE, M., Cryogenics 17 (1977) 111.

[10] Jeapes, A. P., Thesis, School of Chemistry, University of. Bristol (1973).

[11] Anderson, P. W., Halperin, B. I. and Varma, C. M., Philos. Mag. 25 (1972) 1.

[12] Phillips, W. A., J. Low Temp. Phys. 7 (1972) 351.

[13] Lyon, K. G., Salinger, G. L. and Swenson, C. A., Phys. Rev. B 19 (1979) 4231.

[14] Zeller, R. C. and PoHl, R. O., Phys. Rev. B 4 (1971) 2029.

[15] White, G. K. and BirCH, J. A., Phys. Chem. Glasses 6 (1965) 85 . 